\title{
La formación académica del director coral y sus herramientas para el desarrollo de coros infantiles. Situación actual en Costa Rica y España
}

\author{
Choral Conducting Studies and Tools Required for the Development of Children's Choirs. \\ Current Situation in Costa Rica and Spain
}

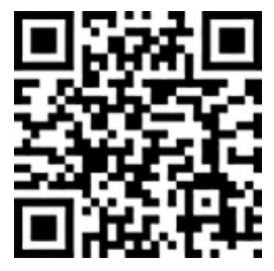

\author{
Carlos Fernando Chaves-Cordero ${ }^{1}$ \\ Universidad Rey Juan Carlos \\ Madrid, España \\ cfernandoch@hotmail.com \\ http://orcid.org/0000-0002-2138-0423 \\ Catalina Escamilla-Fonseca ${ }^{2}$ \\ Universidad Autónoma de Madrid \\ Madrid, España \\ escamilla.pimu@gmail.com \\ http://orcid.org/0000-0001-6150-4497
}

\footnotetext{
${ }^{1}$ Máster en Creación e Interpretación Musical por la Universidad Rey Juan Carlos, España. Graduado en Música con Énfasis en Interpretación y Enseñanza de la Dirección Coral por la Universidad Nacional de Costa Rica. Se ha desempeñado como director de agrupaciones corales mixtas e infantiles, en escuelas de música, universidades y para la comunidad. Ha recibido formación en dirección coral en el Instituto Kodály en Hungría, así como en Irlanda, Argentina y Cuba, además de haber realizado giras internacionales con sus agrupaciones a Panamá y El Salvador. Es director de Musicaeduca en Costa Rica.

${ }^{2}$ Máster en Calidad y Mejora de la Educación por la Universidad Autónoma de Madrid, España. Graduada en Música con Énfasis en Educación Musical por la Universidad Nacional de Costa Rica. Se ha desempeñado principalmente en la pedagogía musical en primera infancia. Fue parte del equipo de investigación del proyecto ERASMUS+ de la Unión Europea para el Aprendizaje-Servicio en la educación superior. Consultora del programa Música para la Niñez de UNICEF. Ha recibido formación musical en pedagogía musical en Instituto Kodály en Hungría, México, España, Guatemala y Costa Rica. Es coordinadora académica de Musicaeduca en Costa Rica.
} 
doi: http://dx.doi.org/10.15359/ree.21-1.5

URL: http://www.una.ac.cr/educare

CORREO: educare@una.cr

Resumen:La presente investigación cualitativa se desarrolla con el objetivo de comprender la situación actual de la formación académica del director o directora coral en Costa Rica y España, haciendo énfasis en las herramientas que adquieren para su desempeño con los coros infantiles. Realiza un análisis documental por medio de la técnica FODA, en el cual se analizan los planes de estudio de las carreras de dirección coral de la Universidad Nacional de Costa Rica y del Real Conservatorio Superior de Música de Madrid. El estudio de los planes se enfoca principalmente en las asignaturas relacionadas con la pedagogía y el canto, como bases imprescindibles en el área específica del canto coral infantil. Así mismo, a través del análisis de entrevistas realizadas a directores y directoras corales de ambos países, seleccionados según formación académica y experiencia, se pueden visualizar sus prácticas en cuanto a su desempeño con los coros infantiles y las herramientas adquiridas en su educación superior y se resalta su percepción acerca de qué se debería cambiar o ajustar en los planes de estudio. Se perciben importantes carencias en la formación pedagógica en las asignaturas de la carrera, y se sugiere una reestructuración con más contenidos en metodologías pedagógicas y recursos.

Palabras claves: Formación coral; director o directora coral; coro infantil.

\begin{abstract}
This qualitative research seeks to understand the current situation of choral conducting studies in Costa Rica and Spain, emphasizing on the tools required to work with children's choirs. The curriculum of choral conducting careers at the Universidad Nacional de Costa Rica and the Real Conservatorio Superior de Música de Madrid was studied by means of an analysis of documents and an analytic comparison with the SWOT method. The study of plans primarily focused on subjects related to pedagogy and singing as essential foundations in the specific area of children's choirs. Additionally, an analysis of interviews to choral directors from both countries visualized the experiences of directors in their performance with children's choirs, what skills were acquired in their undergraduate education, as well their perception of what should change or adjust in the curriculum. Significant shortcomings were perceived in teacher's training in relation with the subjects of the career. A strengthening with more contents in teaching methodologies and pedagogical resources was suggested.
\end{abstract}

Keywords: Choral conducting studies; choral conductor; children's choir.

\title{
Introducción
}

La amplia presencia de coros infantiles en distintos espacios de la sociedad, como conservatorios y programas pre-universitarios, escuelas de música, instituciones de enseñanza general, centros culturales o religiosos, exigen por sí misma la guía de un director o directora. Esta figura de dirección se ha consolidado cada vez más en los espacios académicos y profesionales. Sin embargo, en muchos casos, los coros infantiles son guiados por docentes en educación musical y no por directores o directoras. La experiencia de vivir en Costa Rica y en España, y palpar en ambos países el desempeño de los coros infantiles y su personal de dirección, nos lleva a cuestionarnos si su formación académica en ambas naciones iberoamericanas contempla las herramientas pedagógicas necesarias para el ejercicio de la actividad coral infantil. 
Para la estructura de la investigación, se han tomado dos centros de interés. El primero de ellos, el de conocer, analizar y comparar la formación superior de directores corales en Costa Rica y España, en cuanto a las herramientas que obtienen para su desempeño profesional con los coros infantiles. Como segundo punto, el de darles voz como protagonistas, de manera que puedan, a través de su experiencia, pronunciarse abiertamente ante este tema.

\section{Coros infantiles, definición y características}

Se define el coro infantil como la agrupación vocal conformada por voces blancas ${ }^{3}$. Generalmente se ha consensuado que existe similitud en tesitura de estas voces con la de las mujeres adultas (Castro, 2003). No obstante, Molina, Fernández, Vázquez, y Urra (2006), en el artículo publicado en la revista médica de la Universidad de Navarra, explican que la voz de los niños es más aguda que la de una persona adulta del sexo femenino, ya que su laringe es pequeña y similar en tamaño hasta los 13 años, y, al llegar la pubertad, en las mujeres la voz suele descender alrededor de 4 semitonos, mientras que en los hombres ronda la octava. Al momento del nacimiento, la laringe posee unos 4,5 o 5 milímetros de tamaño, que es una tercera parte de la de una mujer adulta, y se encuentra en una posición alta en el cuello en la tercera vértebra cervical (C3) hasta que en la pubertad se asienta definitivamente en las últimas vértebras cervicales (C6-C7). Por todo lo anterior, se recomienda que su clasificación utilice los términos de "primera voz", "segunda voz" y "tercera voz", a su vez, la ubicación de los niños en cada sección debe responder a sus timbres y capacidades vocales, ya que, aunque la mayoría por naturaleza son sopranos, existen quienes poseen timbres más oscuros y sonidos más graves.

\section{Tendencias pedagógicas en la dirección coral infantil}

En vista de la actividad musical y coral que existe, surge la necesidad de la figura de un líder que, como tal, logre no solo transmitir las ideas y conceptos musicales, sino también que estos se conviertan en aprendizaje para los niños y niñas. Para esto, es sumamente necesario que el director o directora de un coro infantil domine, además de las destrezas teóricas y técnicas musicales que exige su profesión, la experiencia de la pedagogía musical.

Durante la historia de la música, han surgido personajes de gran importancia en la pedagogía de la música, que han tomado de referencia los coros infantiles y la educación vocal como principal herramienta de aprendizaje. Aunque se han creado métodos que involucran directamente la actividad coral infantil y otros únicamente el uso de la voz, ideas plasmadas en métodos como Kodály, Chevais, Ward, Martenot u Orff le pueden facilitar a la dirección coral herramientas para el desarrollo de los ensayos y el avance técnico y musical del grupo. Desde el

\footnotetext{
${ }^{3}$ Se denomina voces blancas a las voces que no han sufrido cambios físicos y tímbricos por la pubertad.
} 
doi: http://dx.doi.org/10.15359/ree.21-1.5

URL: http://www.una.ac.cr/educare

CORREO: educare@una.cr

punto de vista técnico y musical, no se puede olvidar que el coro será un espacio de aprendizaje donde la música se aprende desde la experiencia.

Kodály ... enfatiza la producción vocal y en especial la coral. ... Esta ideología, expresada sintéticamente en la frase "A zene mindekié", "Que la música pertenezca a todos" otorga a la voz humana el rol principal como instrumento expresivo. Instrumento que todos los seres humanos poseen. Implica que los coros son un medio de expresión artística y constituyen un laboratorio formativo al servicio del arte. (Miró, 2011, p. 12)

Miró (2011), a través de las ideas de este compositor, ubica los coros como un "laboratorio formativo al servicio del arte" (p. 12). Este concepto se convierte en un importante centro de atención cuando de calidad musical se trata. El objetivo no se encuentra en difundir la práctica musical sin más propósito, sino, más bien, de que el quehacer musical sea de calidad, de manera que el pueblo pueda comprenderlo a fondo, en otras palabras, alfabetizar musicalmente al pueblo. Esta alfabetización comienza desde la niñez, tal y como Miró (2011) relata, "Kodály concibe a los niños como capaces de abordar y resolver aprendizajes musicales de alto nivel, tomando en cuenta sus etapas de desarrollo y un entrenamiento musical adecuado" (p. 17).

\section{Retos pedagógicos para la dirección coral infantil}

Desde el punto de vista médico, el mal uso de la voz en la niñez, que naturalmente puede tener su origen en una deficiente y pobre experiencia o conocimiento pedagógico de la enseñanza del canto para las voces blancas, puede acarrear problemas de compromiso ético y hasta legal por parte de los directores o directoras debido a posibles patologías vocales que puedan experimentar a corto, mediano o largo plazo (Molina et al., 2006).

Por ello, resulta de vital relevancia para quien dirige coros infantiles comprender la importancia del canto en la formación musical de la niñez y su correcta enseñanza. Ferrer (2009) insiste en la importante participación del oído, la vista y el tacto en conjunto con la voz en el aprendizaje musical. De esta manera, se entiende que el desarrollo de las habilidades musicales, desde el canto, permite ampliar el autoconocimiento por medio de las sensaciones, y así la interiorización de cada elemento musical, técnico e interpretativo, se torna más vivencial (Piñeros, 2004).

Cuando nos centramos en coros infantiles de instituciones de enseñanza musical, se debe tener claro que los grupos están conformados por músicos y músicas en formación. El coro es el lugar idóneo donde todos los elementos de autoconocimiento físico y abstracto se pueden fusionar en la percepción de quienes se forman, y así, desde la infancia, desarrollar habilidades musicales que no solamente lograrán hacerles comprender la música más allá de la lectura de las notas, sino que con mayor facilidad, gracias a las experiencias vividas, transmitirán y utilizarán esos recursos en el proceso de madurez con sus respectivos instrumentos. 
Sin embargo, como resaltan Ibarretxe y Díaz (2008):

Los directores de los coros infantiles trabajan mucho la voz, pero no tanto otros aspectos como la expresión corporal y el movimiento. Se ve la necesidad de que la formación de esos directores incida también en esos aspectos $y$, a su vez, se echan en falta otro tipo de conocimientos pedagógicos que faciliten el trabajo con los niños. ... Además, se insiste en el carácter específico de la labor del director de coros infantiles y su importancia en la educación musical en general, de ahí la preocupación por clarificar el papel que juegan éstos en las diferentes actividades corales (pp. 12-13).

Ibarretxe y Díaz (2008), al recordar los temas tratados en la Conferencia Europa Cantat, reafirman la necesidad de una formación más clara y especializada en cuanto a los temas de coros de voces blancas. Tal y como Gustems y Elgstrom (2008) indican, la dirección ejerce dos funciones: una docente y otra conductora de grupo. La necesidad pedagógica que requieren estos líderes artísticos es realmente muy fuerte, si logramos entender esta dualidad de funciones.

\section{Formación inicial del director o directora coral en España}

En España, la formación superior de los directores y directoras se cursa en los Reales Conservatorios Superiores. Según el Boletín Oficial de la Comunidad de Madrid N ${ }^{\circ} 141$ del 16 de junio de 2011, el Plan de estudios de la carrera de Dirección en el Real Conservatorio Superior de Música de Madrid (Consejo de Gobierno, 2011) se distribuye de la siguiente manera (ver Tabla 1):

En la Tabla 1 se puede observar que se imparten dos años consecutivos de educación vocal en clases grupales, además de la ausencia total de asignaturas referentes a pedagogía.

Tabla 1: Plan curricular especialidad de dirección, Conservatorio Superior de Música de Madrid

\begin{tabular}{|c|c|c|c|}
\hline \multicolumn{4}{|c|}{ Título Superior de Música con Especialidad en Dirección } \\
\hline $\begin{array}{l}\text { I Año Lectivo/ } \\
\text { Asignaturas }\end{array}$ & $\begin{array}{l}\text { II Año Lectivo/ } \\
\text { Asignaturas }\end{array}$ & $\begin{array}{l}\text { III Año Lectivo/ } \\
\text { Asignaturas }\end{array}$ & $\begin{array}{l}\text { IV Año Lectivo/ } \\
\text { Asignaturas }\end{array}$ \\
\hline Historia de la Música I & Historia de la Música II & Estética y Filosofía de la Música I & Educación Auditiva IV \\
\hline Análisis I & Análisis II & Educación Auditiva III & Inglés Aplicado a la Música I \\
\hline Armonía I & Armonía II & $\begin{array}{l}\text { Instrum. Complementario } \\
\text { Cuerda/Viento I } \\
\text { (clase individual) }\end{array}$ & $\begin{array}{l}\text { Instrumento Complementario } \\
\text { Cuerda/Viento II } \\
\text { (clase individual) }\end{array}$ \\
\hline Educación Auditiva I & Educación Auditiva II & Reducción de Partituras II & $\begin{array}{l}\text { Piano Complementario IV } \\
\text { (clase individual) }\end{array}$ \\
\hline
\end{tabular}


doi: http://dx.doi.org/10.15359/ree.21-1.5

URL: http://www.una.ac.cr/educare

CORREO: educare@una.cr

\section{Título Superior de Música con Especialidad en Dirección}

\begin{tabular}{|c|c|c|c|}
\hline $\begin{array}{l}\text { I Año Lectivo/ } \\
\text { Asignaturas }\end{array}$ & $\begin{array}{l}\text { II Año Lectivo/ } \\
\text { Asignaturas }\end{array}$ & $\begin{array}{l}\text { III Año Lectivo/ } \\
\text { Asignaturas }\end{array}$ & $\begin{array}{l}\text { IV Año Lectivo/ } \\
\text { Asignaturas }\end{array}$ \\
\hline $\begin{array}{l}\text { Educación Vocal I } \\
\text { (clase colectiva) }\end{array}$ & $\begin{array}{l}\text { Educación Vocal II } \\
\text { (clase colectiva) }\end{array}$ & $\begin{array}{l}\text { Piano Complementario III } \\
\text { (clase individual) }\end{array}$ & $\begin{array}{l}\text { Armonía y Contrapunto de los } \\
\text { s. XX y XXI II }\end{array}$ \\
\hline $\begin{array}{l}\text { Piano Complementario I } \\
\text { (clase individual) }\end{array}$ & $\begin{array}{l}\text { Reducción de } \\
\text { Partituras I }\end{array}$ & $\begin{array}{l}\text { Armonía y Contrapunto de los } \\
\text { s. XX y XXI I }\end{array}$ & $\begin{array}{l}\text { Instrumentación y } \\
\text { Orquestación II }\end{array}$ \\
\hline $\begin{array}{l}\text { Prácticas de Orquesta / } \\
\text { Banda /Coro / Canto Llano } \\
\text { y Conjunto Vocal }\end{array}$ & $\begin{array}{l}\text { Piano Complementario II } \\
\text { (clase individual) }\end{array}$ & $\begin{array}{l}\text { Instrumentación y } \\
\text { Orquestación I }\end{array}$ & $\begin{array}{l}\text { Análisis del Repertorio } \\
\text { Sinfónico, Coral y Dramático II }\end{array}$ \\
\hline Contrapunto I & $\begin{array}{l}\text { Prácticas de Orquesta / } \\
\text { Banda /Coro / Canto Llano } \\
\text { y Conjunto Vocal II }\end{array}$ & $\begin{array}{l}\text { Análisis del Repertorio Sinfónico } \\
\text { coral y Dramático I }\end{array}$ & $\begin{array}{l}\text { Idiomas aplicados a la } \\
\text { dirección de coros II }\end{array}$ \\
\hline Técnica de la Dirección & Contrapunto II & $\begin{array}{l}\text { Idiomas aplicados a la dirección } \\
\text { de coros I }\end{array}$ & Técnica de la dirección IV \\
\hline $\begin{array}{l}\text { Técnicas de Ensayo y } \\
\text { Concertación }\end{array}$ & $\begin{array}{l}\text { Fundamentos y Mecánica } \\
\text { de los Instrumentos } \\
\text { Orquestales I }\end{array}$ & Repertorio coral y orquestal I & $\begin{array}{l}\text { Técnicas de Ensayo y } \\
\text { Concertación IV }\end{array}$ \\
\hline \multirow[t]{3}{*}{ Acústica Musical Aplicada I } & Técnica de la Dirección II & Técnica de la dirección III & \\
\hline & $\begin{array}{l}\text { Técnicas de Ensayo y } \\
\text { Concertación II }\end{array}$ & $\begin{array}{l}\text { Técnicas de ensayo y } \\
\text { concertación III }\end{array}$ & \\
\hline & & Informática musical I & \\
\hline \multicolumn{4}{|l|}{ Total de créditos: 205} \\
\hline \multicolumn{3}{|l|}{ Total de horas: 5.125 / 6.150} & 1 crédito ECTS $=25-30$ horas \\
\hline
\end{tabular}

Nota: Elaboración propia a partir del Consejo de Gobierno (pp. 50-72).

\section{Formación inicial del director o directora coral en Costa Rica}

En Costa Rica, la carrera de Dirección se cursa en dos universidades estatales, la Universidad Nacional de Costa Rica (UNA) y la Universidad de Costa Rica (UCR), y no existen en el país universidades privadas que ofrezcan el programa.

Según el Plan de Estudios de la Dirección Coral de la Universidad Nacional de Costa Rica. Escuela de Música (s. f.), los cursos de la especialidad de música con énfasis en interpretación y enseñanza de la dirección coral se distribuyen de la siguiente manera (ver Tabla 2 y 3): 
doi: http://dx.doi.org/10.15359/ree.21-1.5

URL: http://www.una.ac.cr/educare

CORREO: educare@una.cr

Tabla 2: Plan Curricular de Bachillerato en Dirección Coral de la Universidad Nacional de Costa Rica

\begin{tabular}{|c|c|c|c|}
\hline \multicolumn{4}{|c|}{ Bachillerato (grado) en Música con Énfasis en la Interpretación y Enseñanza de la Dirección Coral } \\
\hline $\begin{array}{l}\text { I Año Lectivo/ } \\
\text { Asignaturas }\end{array}$ & $\begin{array}{l}\text { Il Año Lectivo/ } \\
\text { Asignaturas }\end{array}$ & $\begin{array}{l}\text { III Año Lectivo/ } \\
\text { Asignaturas }\end{array}$ & $\begin{array}{l}\text { IV Año Lectivo/ } \\
\text { Asignaturas }\end{array}$ \\
\hline Estudios Generales & Piano para Dirección Coral II & Estudios Generales & Optativo \\
\hline Lenguaje Musical I & Canto para Dirección Coral II & Optativo & Análisis Musical I \\
\hline $\begin{array}{l}\text { Piano para Dirección Coral I } \\
\text { (clase individual) }\end{array}$ & Historia de la Música II & $\begin{array}{l}\text { Piano para Dirección Coral V } \\
\text { (clase individual) }\end{array}$ & $\begin{array}{l}\text { Manejo instrumental del } \\
\text { Idioma I }\end{array}$ \\
\hline $\begin{array}{l}\text { Canto para Dirección Coral I } \\
\text { (clase individual) }\end{array}$ & Dicción Lírica ll & $\begin{array}{l}\text { Canto para Dirección Coral V } \\
\text { (clase individual) }\end{array}$ & Dirección Coral Principal II \\
\hline Historia de la Música I & Lenguaje Musical III & Dirección Coral Principal I & Literatura Coral I \\
\hline $\begin{array}{l}\text { Introducción a la Dirección } \\
\text { Coral }\end{array}$ & $\begin{array}{l}\text { Piano para Dirección Coral III } \\
\text { (clase individual) }\end{array}$ & Pedagogía en Dirección Coral I & Taller de Práctica Coral II \\
\hline Dicción Lírica I & $\begin{array}{l}\text { Canto para Dirección Coral III } \\
\text { (clase individual) }\end{array}$ & Armonía y Polifonía I & Optativo \\
\hline Taller Coral I & Historia de la Música III & Taller de Práctica Coral I & Análisis Musical II \\
\hline Estudios Generales & Técnicas de Dirección Coral & Optativo & $\begin{array}{l}\text { Práctica Profesional } \\
\text { Supervisada }\end{array}$ \\
\hline Lenguaje Musical II & Armonía I & $\begin{array}{l}\text { Piano para Dirección Coral VI } \\
\text { (clase individual) }\end{array}$ & Tecnología Musical \\
\hline $\begin{array}{l}\text { Piano para Dirección Coral II } \\
\text { (clase individual) }\end{array}$ & Taller Coral II & $\begin{array}{l}\text { Canto para Dirección Coral VI } \\
\text { (clase individual) }\end{array}$ & Literatura Coral II \\
\hline $\begin{array}{l}\text { Canto para Dirección Coral II } \\
\text { (clase individual) }\end{array}$ & Estudios Generales & Pedagogía en Dirección Coral II & \\
\hline Historia de la Música II & Lenguaje Musical IV & Armonía y Polifonía II & \\
\hline \multirow[t]{4}{*}{ Dicción Lírica II } & $\begin{array}{l}\text { Piano para Dirección Coral IV } \\
\text { (clase individual) }\end{array}$ & & \\
\hline & $\begin{array}{l}\text { Canto para Dirección Coral IV } \\
\text { (clase individual) }\end{array}$ & & \\
\hline & Historia de la Música IV & & \\
\hline & Armonía II & & \\
\hline \multicolumn{4}{|l|}{ Total de créditos: 142} \\
\hline
\end{tabular}

Nota: Elaboración propia a partir de UNA. Escuela de Música (s. f.). 
doi: http://dx.doi.org/10.15359/ree.21-1.5

URL: http://www.una.ac.cr/educare

CORREO: educare@una.cr

Tabla 3: Plan Curricular de Licenciatura en Dirección Coral de la Universidad Nacional de Costa Rica

\begin{tabular}{lc}
\hline \multicolumn{1}{c}{$\begin{array}{c}\text { Licenciatura en Música con Énfasis en la Interpretación y } \\
\text { Enseñanza de la Dirección Coral }\end{array}$} & II Año Lectivo/ Asignaturas \\
\hline Dirección Coral I de Licenciatura & Seminario de Dirección Coral \\
Seminario de Literatura Coral & Optativo \\
Piano I para Licenciatura en Dirección Coral (clase individual) & Recital \\
Canto I para Licenciatura en Dirección Coral (clase individual) & Pedagogía Coral Especializada \\
Manejo Instrumental del Idioma II & Ética y Currículum Musical \\
Piano II para Licenciatura en Dirección Coral (clase individual) & Trabajo Final de Graduación \\
Canto II para Licenciatura en Dirección Coral (clase individual) & \\
\hline Total de créditos: $\mathbf{3 6}$ & \\
\hline
\end{tabular}

Nota: Elaboración propia a partir de UNA. Escuela de Música (s. f.).

En el plan de estudios de Costa Rica, se puede notar que incluye tres años de canto, o educación vocal en clases individuales, con un año más en la especialización o licenciatura, para un total de cuatro años. Por otro lado, se incluyen dos asignaturas de pedagogía en el programa de grado, y una más para la licenciatura. Todo esto en contraste con los dos años de educación vocal y la omisión de asignaturas pedagógicas en España.

\section{Metodología}

Se ha realizado un análisis documental en el cual se estudian los planes de estudio de las carreras de dirección coral presentes en Costa Rica y España, así como entrevistas que se realizaron a 9 directores y directoras corales en ambos países.

Se utilizó, como técnica de análisis de datos, una metodología mixta, comparada y analítica, con el objetivo de comprender la situación actual de la formación académica de dirección coral en Costa Rica y España, con énfasis en las herramientas que adquieren para su desempeño con los coros infantiles. Para el análisis de los planes de estudio de la carrera de dirección coral en Costa Rica y España se ha seleccionado la técnica FODA. 
Así mismo, para conocer la percepción de los directores y directoras corales, se ha elaborado un cuestionario cualitativo con preguntas abiertas, las cuales, tras la lectura de la bibliografía correspondiente a la formación en la dirección coral infantil y los objetivos de la presente investigación, se han dividido en las siguientes categorías: (1) Formación para la dirección coral, (2) Competencias que se requieren para el desarrollo de coros infantiles, (3) Propuestas para la formación académica relevante en la dirección coral infantil.

En la Tabla 4 se presentan de forma detallada las preguntas realizadas en el cuestionario:

Tabla 4: Cuestionario para los directores y directoras corales

\section{Categoría I: Formación para la dirección coral}

En esta categoría se toma en cuenta la formación en cuanto a las asignaturas

y los recursos que estas brindan para el trabajo coral infantil

\section{Pregunta 1:}

Durante sus estudios superiores, ¿cursó asignaturas específicas para el trabajo coral infantil?

\section{Pregunta 2}

En su formación superior, ¿considera que obtuvo los recursos vocales y de dirección suficientes para comenzar a trabajar con coros de niños?

\section{Pregunta 3}

¿Han sido útiles y aplicables en la práctica?

\section{Pregunta 4}

En las diversas dificultades técnico-musicales, vocales y de comportamiento de la niñez, ¿ha tenido suficiente bibliografía de consulta paraapoyar oguiar sus decisiones, así como material de trabajo (partituras)? Si la respuesta es positiva, ¿el material fue facilitado o referido durante su formación académica, o por adquisición personal?

\section{Pregunta 5}

¿En algún momento fue integrante de un coro infantil? Si su respuesta es positiva, ¿esta experiencia ha colaborado en su quehacer de dirección coral?
Con esta interrogante se pretende conocer si el programa de estudios de su carrera incluía asignaturas que pretendieran en alguna medida brindar herramientas básicas para el desempeño con los coros infantiles.

A través de la experiencia en el aula como en el desempeño de sus funciones de dirección, se pretende conocer la percepción de directores y directoras acerca de, si al finalizar sus carreras, poseían las herramientas básicas para enfrentarse a la formación de coros infantiles.

Si consideran que obtuvieron los recursos básicos necesarios, es importante conocer si en la práctica fueron estos aplicables con los resultados esperados.

Si se toma en cuenta que es importante el material de consulta que se pueda poseer; en el caso específico de los coros infantiles, se busca descubrir si en su formación, los directores y directoras reciben material de referencia en este tema.

Si existió la experiencia propia en la niñez, se espera conocer si esta experiencia tuvo repercusiones directas en la motivación para dedicarse a la dirección, si la experiencia le brindó recursos experienciales para su desempeño con los coros infantiles, o bien, otros tipos de influencias. 
doi: http://dx.doi.org/10.15359/ree.21-1.5

URL: http://www.una.ac.cr/educare

CORREO: educare@una.cr

Categoría II: Competencias del director o directora de coros infantiles

La segunda categoría se divide en tres subcategorías

\section{Dominio general en cuanto a fisonomía, fisiología y técnica vocal para las voces blancas}

\section{Pregunta 6}

Para usted, ¿qué características diferenciadoras poseen los coros infantiles en comparación con los coros de voces mixtas?

Pregunta 7

¿Utiliza con los niños y las niñas la técnica vocal que se aplica a las personas adultas? ¿Por qué?
Con esta interrogante se busca conocer los conceptos que cada director o directora posee en cuanto al desarrollo físico, tímbrico y en general, vocalmente de los niños y niñas, antes de llegar a la etapa de la pubertad.

Con base en la pregunta anterior, y los conceptos que los directores y directoras posean, si aplican ejercicios, ejemplos, y otros recursos vocales en igual manera con ambos tipos de coros.

2. Hace referencia al desarrollo musical integral en los coros infantiles, tomando en cuenta la importancia que pueda tener el espacio musical que se obtiene con los grupos corales para aplicar de forma conjunta una serie de aprendizajes musicales

\section{Pregunta 8}

¿Considera importante en la formación musical de la niñez la participación en un coro? Si su respuesta es positiva, indique, ¿qué aspectos cree que fortalece y por qué? Si su respuesta es negativa, indique por qué igualmente.

\section{Pregunta 9}

Durante el proceso de enseñanza y montaje de la música, ¿busca que los niños y niñas comprendan y realicen los elementos referentes a los distintos estilos y géneros musicales, así como fraseos, dinámicas, articulación, entre otros?

\section{Pregunta 10}

Si lo realiza, ¿el grupo ha respondido positivamente? Si lo ha hecho, ¿por qué considera que lo han logrado comprender? Si no lo han conseguido, ¿por qué considera que eso sucede?
Con esta primera interrogante, se pretende conocer sus percepciones acerca de la importancia de la actividad coral no solo como foco de desarrollo moral, psicológico y social, sino también en la formación musical, como ente formador en este arte.

A partir de las percepciones anteriores, se conduce más puntualmente hacia la aplicación empírica. Conocer si buscan que la agrupación coral infantil, al menos de forma básica y general, obtenga consciencia de las diferencias sobre los estilos y géneros musicales, de compositores y sus épocas o de los elementos que aparecen en las partituras escritas.

A partir de este punto, se podrían encontrar conceptos pedagógicos, recursos de ensayos o incluso las ideologías de trabajo que poseen los distintos directores y directoras, y conocer si existe similitud de estos entre las prácticas de cada país.

3. Se centra en el sistema de trabajo durante los ensayos, es decir, en los recursos pedagógicos que poseen quienes dirigen. Para ello, las interrogantes se conducen sobre el conocimiento que tengan los sujetos entrevistados acerca de las distintas metodologías pedagógicas de la enseñanza musical

\section{Pregunta 11}

¿Cree que trabajar con coros infantiles difiere del trabajo con coros de personas adultas? ¿Por qué?
En esta ocasión, se hace énfasis en las diferencias o similitudes en el desarrollo de los ensayos de los coros infantiles respecto a los adultos. Se toma en cuenta cualquier aspecto que involucre la forma de enseñanza, lenguaje, distribución de ensayos, entre otros. 


\section{Pregunta 12}

¿Ha utilizado con los coros en algún momento recursos de métodos pedagógicos, como Kodály, Orff, Ward o algún otro?

Pregunta 13

Si lo ha utilizado, ¿en dónde conoció o aprendió estos métodos?
Con base en este cuestionamiento, se pretende descubrir si conocen alguno(s) de los métodos pedagógicos que se han desarrollado a través de la historia.

De forma adjunta a la anterior, en este inciso se podrá entrever si el material que hayan utilizado fue facilitado o bien motivado en su formación académica.

Tercera categoría: Propuestas para la formación académica

En esta categoría se esperan las recomendaciones que puedan brindar os directores y directoras a partir de su experiencia, para la formación superior en dirección.

Pregunta 14

¿Cómo consideraría una adecuada formación académica para el director o directora, en cuanto a la dirección de coros infantiles?
Se refiere a las recomendaciones que pueden dar a la formación académica en la carrera de dirección, referente a los recursos obtenidos para el trabajo coral infantil, a través de las experiencias vividas al momento de enfrentarse a este tipo de agrupaciones

Nota: Elaboración propia.

\section{Participantes}

Para la selección de los directores y directoras participantes en el cuestionario, se han tenido en cuenta los siguientes criterios de inclusión: (1) a directores o directoras corales que hayan egresado de un título superior de Dirección en alguno de los dos países, o bien estudiantes avanzados del programa, (2), con experiencia en el trabajo de coros de voces blancas. Además, se ha buscado la variedad en los ámbitos de trabajo de cada director o directora (3) docentes de universidad o conservatorios superiores, coros de escuela primaria, religiosos o escolanía, escuelas de música, independientes, o de formación preuniversitaria o conservatorio.

\section{Resultados y discusión}

\section{Análisis FODA de los planes de estudio}

Para la confección del análisis se han seleccionado las asignaturas que se refieren a la formación vocal y pedagógica en dirección, ya que, como muestra la bibliografía, estos repercuten directamente en el desempeño del director o directora para el trabajo específico con los coros infantiles. No por ello se resta importancia a las demás asignaturas que brindan una formación integral. 
doi: http://dx.doi.org/10.15359/ree.21-1.5

URL: http://www.una.ac.cr/educare

CORREO: educare@una.cr

\section{Fortalezas y oportunidades}

Se toman en cuenta, como fortalezas, aquellos aspectos positivos que poseen los planes de estudio. Como oportunidades, se consideran los conocimientos, competencias o prácticas positivas que se podrían generar a partir de las fortalezas que poseen los programas (ver Tabla 5).

Tabla 5: Fortalezas y oportunidades en la formación vocal y pedagógica en dirección coral

\begin{tabular}{|c|c|c|}
\hline País & Asignaturas & Descripción \\
\hline \multicolumn{3}{|c|}{ Fortalezas y oportunidades: Formación vocal } \\
\hline Costa Rica & $\begin{array}{l}\text { - Canto para Dirección } \\
\text { Coral I, II, III, IV, V, VI } \\
\text { - Canto para Dirección Coral } \\
\text { en Licenciatura I, II. }\end{array}$ & $\begin{array}{l}\text { La asignatura de Canto se imparte durante tres años consecutivos } \\
\text { y en clases individuales, añadiendo un año más para los dos años } \\
\text { de especialización (Licenciatura). Esto le permite al director o } \\
\text { directora en formación dominar mayor cantidad de conceptos } \\
\text { y superar mejor las dificultades vocales para su aplicación y } \\
\text { enseñanza. }\end{array}$ \\
\hline España & • Educación Vocal I, II & $\begin{array}{l}\text { La asignatura de Educación Vocal se imparte de forma grupal, lo } \\
\text { que permite conocer las distintas dificultades técnicas vocales de } \\
\text { los miembros del grupo, y cómo abarcarlas para darles solución, } \\
\text { por lo que brinda herramientas de trabajo. }\end{array}$ \\
\hline
\end{tabular}

En ambos países los planes incluyen cursos de canto, asignaturas vitales para la formación en dirección coral, debido a la responsabilidad formadora que adquiere, sobre todo en los coros de escuelas de música o coros aficionados. Esta, permitirá comprender los distintos elementos de la ejecución del canto y, a partir de su experiencia, facilitará de una manera más amplia la enseñanza del canto a los grupos corales.

Fortalezas y oportunidades: Formación pedagógica

\begin{tabular}{lll}
\hline Costa Rica & - Pedagogía Coral I, II & El plan contempla dos cursos (un año) de Pedagogía Coral, \\
& - Pedagogía Coral & asignatura que involucra herramientas para el trabajo con \\
& Especializada & distintos tipos de agrupaciones. Agrega además un curso de \\
& Pedagogía Coral Especializada para los dos años de extensión. \\
& Esto permitirá que el director o directora en formación se enfrente \\
& a su trabajo con herramientas básicas para la enseñanza, una de \\
& las principales bases para conducir los grupos corales hacia los \\
& objetivos musicales.
\end{tabular}

Nota: Elaboración propia.

\section{Debilidades y amenazas}

Se consideran debilidades aquellos aspectos de los que los programas de estudio carecen, o bien, su manera de ser planteados no brinda las suficientes bases para el desempeño del personal egresado. Como amenazas, se toman en cuenta aquellas acciones negativas que pueden suceder en la práctica, como consecuencia de las debilidades en el plan de estudios (ver Tabla 6). 
Tabla 6: Debilidades y amenazas en la formación vocal y pedagógica en dirección coral

\begin{tabular}{ccc}
\hline \multicolumn{1}{c}{ País } & \multicolumn{1}{c}{ Descripción } \\
\hline Costa Ricaturas & Debilidades y amenazas: Formación vocal \\
\hline & $\begin{array}{c}\text { - Canto para Dirección } \\
\text { Coral I, II, III, IV, V, VI } \\
\text { - Canto para } \\
\text { Dirección Coral en } \\
\text { Licenciatura I, II }\end{array}$ & $\begin{array}{l}\text { Al enfrentarse a la formación vocal únicamente individual, se puede perder } \\
\text { contacto con otras dificultades técnicas que en otras personas pueden } \\
\text { presentarse, y cómo se pudiesen resolver, según su género (voces masculinas o } \\
\text { femeninas), registro (sopranos, contraltos, tenores, bajos) o edad. }\end{array}$ \\
& - Educación Vocal I, II & $\begin{array}{l}\text { Asignaturas de canto únicamente grupales no permiten una atención } \\
\text { personalizada al estudiantado, por lo que la solución de problemas } \\
\text { técnicos vocales o interpretativos en los directores o directoras en } \\
\text { formación puede tomar mayor cantidad de tiempo, o no desarrollarse lo } \\
\text { suficiente como para poseer las herramientas para solucionar los distintos } \\
\text { aspectos técnicos en los grupos. }\end{array}$ \\
\hline
\end{tabular}

En ambos países la educación vocal se centra únicamente en la ejecución vocal del director o directora en formación, sin contemplar como mínimo el conocimiento de lo anatómico o fisiológico de las voces y sus diferencias en cuanto a género (voces masculinas y femeninas) o edad (voces blancas o voces maduras a distintas edades), e incluso patologías vocales.

El poco conocimiento de las patologías vocales, así como las diferencias anatómicas y fisiológicas de la voz en las diferentes edades, género, o registros, puede desembocar en que los integrantes de los coros lleguen a experimentar distintas patologías vocales, deficientes resultados sonoros, y ciertas frustraciones tanto para los grupos como para el director.

\begin{tabular}{|c|c|c|}
\hline \multicolumn{3}{|c|}{ Debilidades y amenazas: Formación pedagógica } \\
\hline Costa Rica & $\begin{array}{l}\text { - Pedagogía } \\
\text { Coral I, II } \\
\text { - Pedagogía Coral } \\
\text { Especializada }\end{array}$ & $\begin{array}{l}\text { Los programas de pedagogía coral no contemplan ningún contacto con } \\
\text { métodos pedagógicoso conocimientos básicos de los métodos deaprendizaje. } \\
\text { La falta de conocimiento, al menos básico, de las distintas metodologías } \\
\text { pedagógicas, podría desembocar en la monotonía de las funciones artísticas } \\
\text { del director o directora con los grupos, o la repetición de patrones de trabajo } \\
\text { sin distinción de la identidad de las agrupaciones, la cual repercutiría de formas } \\
\text { variadas según los factores de diversidad de los grupos corales ya citados. }\end{array}$ \\
\hline España & & $\begin{array}{l}\text { No existe ninguna asignatura relacionada con la pedagogía aplicada a la } \\
\text { dirección. No poseer las bases pedagógicas suficientes puede desembocar } \\
\text { en la pérdida de atención y orden en las agrupaciones durante los ensayos, } \\
\text { así como interés y motivación. Desde el punto de vista técnico, si la manera de } \\
\text { transmitir los conceptos, tanto en el lenguaje verbal como corporal es pobre, } \\
\text { los miembros de un coro tardarán más tiempo en comprenderlos y aplicarlos. }\end{array}$ \\
\hline
\end{tabular}

En ambos países la carrera se encuentra carente de una asignatura que dote de herramientas suficientes para los primeros contactos con el trabajo coral infantil.

Nota: Elaboración propia. 
doi: http://dx.doi.org/10.15359/ree.21-1.5

URL: http://www.una.ac.cr/educare

CORREO: educare@una.cr

\section{Análisis de entrevistas}

\section{Formación de los directores y directoras corales}

En cuanto al análisis de las entrevistas realizadas de ambos países, se deja ver en los argumentos que existe claramente una formación musical y vocal para el director o directora. Sin embargo, no se le dota de las herramientas necesarias para que estas puedan ser transmitidas al coro.

Los sujetos entrevistados coinciden en la falta de recursos para trabajar o alegan la falta de calidad en el reducido material que se brinda. A manera de ejemplo, para la segunda pregunta, referente a si obtuvieron los recursos vocales y de dirección suficientes, se registran respuestas como:

... muchas veces dentro de la práctica resultaba un poco difícil explicarles a los niños el uso de la técnica ... (Director 3)

... Solo en mis manos tengo un folleto que mi maestra de carrera me facilitó, aunque no era mucho repertorio ... (Director 3)

Sí de dirección, no de recursos vocales. (Director 1)

No la suficiente y la calidad de la misma fue poca. Al trabajar con los coros uno confronta la falta de formación. (Director 8)

En lo que a bibliografía y material de consulta se refiere, los directores y directoras tanto de España como de Costa Rica coinciden claramente en las respuestas. No solamente en que el material suministrado durante su formación ha sido poco o nulo, sino en que el que poseen ha sido adquirido por ellas o ellos mismos.

Bibliografía de consulta ninguna. Material de trabajo, el que yo mismo busqué y/o elaboré. Siempre por adquisición personal. (Director 1)

Por adquisición personal, sin duda. (Director 2)

... La consulta en internet fue complementaria al poco material que poseo. La mayoría del material que se me suministró es en inglés y la menor parte en español. (Director 4)

Existe mucho material al respecto, que adquirí por mis propios medios. (Director 5) 
En el caso del Director 8, quien no solamente cursó la carrera en Dirección, sino que es egresado también de la carrera de Educación Musical, brinda una información que, desde su percepción y para este análisis puede tomar una importante presencia.

Mi experiencia y formación docente me permiten abordar de mejor manera la práctica coral. Sin embargo, los profesores de dirección carecen de conocimiento pedagógico. (Director 8)

Se podría intuir, a partir de este argumento, que aquellas personas músicas que han cursado carreras en pedagogía musical o educación musical poseen más herramientas para transmitir las ideas musicales y técnicas que los propios directores o directoras corales.

Otro de los entrevistados confirma, desde su experiencia, que, en países como Alemania, existe una clara definición de especialidades dentro de la misma rama de la dirección coral. Por esta razón, en sus respuestas se denota su respeto hacia la especialidad, como un área de trabajo que involucra todo un conocimiento específico, aparte del que ya de por sí todos los individuos que dirigen han de tener.

... La Universidad en la que realicé mis estudios de maestría (Alemania) sí ofrece la maestría en dirección de coros infantiles y juveniles. (Director 9)

Con base en las respuestas dadas, se puede deducir que la formación básica en pedagogía para desempeñarse en la dirección de coros infantiles se encuentra pobre o incluso nula en algunos casos. La falta de una asignatura, en el caso de España, o la carencia de contenidos suficientes en el tema de coros infantiles, en el de Costa Rica, generan inconsistencias en los primeros contactos que experimentan los grupos egresados con este tipo de agrupaciones. Advierten la necesidad de conocimiento en esta área, y es perceptible cuando la totalidad afirma haber buscado material por sus propios medios.

\section{Competencias del director o directora de coros infantiles}

\section{Cuidado y manejo de la voz blanca}

En esta subcategoría, se puede obtener información acerca de los conocimientos que los directores y directoras poseen acerca de las voces blancas. Sus características generales, así como la manera de aplicar los recursos técnicos con base en ello. Se denota que la mayoría son conscientes de que existen diferencias físicas y fisiológicas entre las voces blancas y las voces adultas. 
doi: http://dx.doi.org/10.15359/ree.21-1.5

URL: http://www.una.ac.cr/educare

CORREO: educare@una.cr

El aparato fonador y el oído están en un proceso de formación, de crecimiento ... (Director 1)

La técnica vocal, las tesituras, colores y timbres ... (Director 5)

Hay muchos aspectos fisiológicos y psicológicos a considerar. La madurez física de un niño y la dinámica cognitiva es muy diferente. (Director 8)

Sin embargo, no existen descripciones amplias o más específicas en cuanto a estas diferencias de los coros infantiles respecto a los mixtos. Incluso, se deja ver que en algunos casos experimentan dificultades para expresar los conceptos con el lenguaje técnico adecuado.

Voces más puras y "blancas", listas para ser descubiertas y trabajar con ellas, mayor dinámica al ser un "juego" para ellos (Director 7)

El timbre de los niños al ser más suave, los hace más sutiles a la hora de interpretar algún tema ... (Director 3)

En cuanto a la técnica vocal que se imparte a los coros infantiles, coinciden en que esta debe aplicarse de forma distinta a como se aplica con los coros de personas adultas. Una parte del grupo entrevistado comienza su argumento afirmando que los principios de la técnica vocal son los mismos, pero la manera de enseñarlos o aplicarlos es distinta.

Los principios básicos sí. La manera de enseñarlos es diferente. (Director 1)

... He sentido que es una misma técnica vocal pero implementada de una manera más simple ... (Director 3)

... El fundamento de la utilización del aire (respiración) como principal fuente de energía es un concepto universal, pero en la parte física debe ser diferente, por cuestiones del desarrollo aparato fonador. Debe ser adecuado para la etapa de desarrollo físico del niño. (Director 4)

\section{Fomento del desarrollo musical integral en los coros infantiles}

En esta subcategoría, expresarán los aspectos importantes del desarrollo musical y personal de integrantes de los coros infantiles. Los directores o directoras que han trabajado con coros infantiles en escuelas de música son quienes mayormente enfatizan no solo en los aspectos morales y sociales, sino en los de la formación musical de sus integrantes. 
Fortalece el oído, ya que cantar a dos o más voces les ayuda a que el oído sea más armónico. Que a la hora de aprender con más profundidad la música se les dificulte menos la lectura musical. (Director 3)

Sí, ... por el desarrollo auditivo, por la independencia sonora en medios armónicos, por el desarrollo de destrezas emocionales, fomentar las habilidades lingüísticas, entre muchas otras. (Director 5)

Por otra parte, otros directores o directoras, aunque incluyen competencias musicales, hacen un énfasis mayor en el desarrollo de las áreas sociales, morales y psicológicas.

La parte social, la parte cultural, es una actividad lúdica, forma en disciplina, trabajo en grupo. (Director 4)

De esta forma puede ser parte de un grupo, un ensamble, aprende a trabajar en equipo, es una forma de comenzar a socializar con otros niños y hacer amigos. (Director 7)

Las preguntas 10 y 11 nos permiten conocer las formas en que los directores y directoras pueden transmitir las ideas musicales concretas a los grupos infantiles y de qué manera han resultado en sus experiencias. Con base en esto uno de los participantes nos brinda una importante recomendación a partir de su experiencia:

... Señalar una falla es insuficiente. Deben darse los recursos y ejemplos necesarios para cantar la música. Además, se debe alabar cuando hay mejoría en el grupo. Todos queremos hacer las cosas de la mejor manera. Solo necesitamos la guía y las herramientas para alcanzar nuestro mejor nivel. Cuando los niños actúan por el convencimiento propio de hacer su mejor esfuerzo y entienden los elementos que deben mejorar y cómo mejorarlos el disfrute al hacer música es mucho mayor. (Director 9)

La capacidad técnica y musical que el director o directora posea no es suficiente si esta no se puede transmitir con precisión y si no se ostentan las herramientas necesarias para realizarlo. Este director ubica en su argumento los elementos de (1) reconocer los logros alcanzados y (2) reconocer lo que es necesario mejorar, y esto lo muestra como base importante para la motivación de la agrupación infantil, conducida hacia una cada vez mejor calidad.

Por su parte otro participante afirma que:

No es abstracto. Es real y ellos lo hacen: dinámicas y estilos, formas y ritmos. (Director 8) 
doi: http://dx.doi.org/10.15359/ree.21-1.5

URL: http://www.una.ac.cr/educare

CORREO: educare@una.cr

Esto demuestra la idea del aprendizaje de la música desde una perspectiva experiencial, brindando a los grupos infantiles las herramientas para que puedan vivir la actividad musical en los coros más íntima y a la vez en conjunto. Experiencias que, según esta opinión, se pueden tornan cada vez más intensas:

... Comprueban que la calidad en la música es más impactante, creo que los niños viven con intensidad la música cuando está creada artísticamente. (Director 1)

A pesar de esto, se encuentran respuestas con ciertos niveles de discrepancia. Por ejemplo, los siguientes argumentos:

Creo que de una manera general y no tan especializada los niños pueden realizar todo lo que hay en una partitura o lo que proponga el director en cuestión. A veces los elementos formales pueden ser abstractos, por eso creo que el modelaje en todo aspecto (técnico, estilístico y de grafía musical, entre otros) es la mejor herramienta para el aprendizaje ... (Director 4)

Todo niño es capaz de realizar todo lo que el director se proponga a nivel musical. Considero que las dinámicas, frase, articulación y demás, debe enseñarse desde el primer momento del montaje. Si el director no lo tiene claro desde el principio, posiblemente no obtendrá ningún resultado valioso posteriormente. (Director 5 )

Si a esto aunamos el argumento del sujeto participante 8, citado anteriormente "No es abstracto, es real y ellos lo hacen", percibimos la divergencia entre algunas manifestaciones. Mientras el participante 8 indica que no es abstracto, visto desde la experiencia, el director 4 expresa que los elementos formales pueden ser abstractos. Este mismo participante argumenta que se pueden realizar todo lo que existe en una partitura siempre que no sea de una manera especializada, cuando por el contrario el director 5 afirma que se puede realizar todo lo que se proponga, y brinda sus consejos al respecto.

Recordando que, en la primera categoría, los sujetos participantes en su totalidad coincidían con la escasez de material durante su formación académica, por lo que se les hacía necesario conseguirlo por su cuenta a través del tiempo y la experiencia; es natural la presencia de este tipo de desigualdades. Cada director o directora se ha formado con sus propios métodos y ha experimentado vivencias distintas con las agrupaciones, que les han obligado a generar sus propias herramientas, tanto básicas como especializadas, que evolucionan de forma desigual por el desequilibrio presente desde la formación superior. Esto mismo se ve reflejado en los usos tan diversos del lenguaje técnico, el pobre uso de este o incluso la dificultad para utilizarlo. 


\section{Metodologías pedagógicas}

Los distintos directores y directoras muestran un conocimiento muy diverso en cuanto a los métodos pedagógicos. La mayoría coincide en conocer y utilizar métodos como Kodály y Orff, sin embargo, un grupo menor afirma nunca haber utilizado recursos de estos métodos o siquiera conocerlos. Otra parte de participantes nombra otros métodos como Willems, Wytack o Curwen como parte de sus recursos para el trabajo con los coros infantiles.

Uno de los participantes afirma no obtener los resultados esperados:

Kodály y Orff, ambos con resultados muy distintos a los esperados. Los niños latinoamericanos no responden igual a otros de distintas latitudes. Tal vez por idiosincrasia, o biotipo o una mezcla de todo... (Director 5)

Su inquietud, podría demostrar el requerimiento de conocer y estudiar más acerca de metodologías pedagógicas más modernas y que hayan sido diseñadas en Latinoamérica; información necesaria de actualizar en las asignaturas de formación, al menos como referencia para desarrollarse más en esta área.

Las metodologías pedagógicas utilizadas en su mayoría fueron aprendidas de manera autodidacta.

\section{Propuestas para la formación académica}

A través de las experiencias vividas por los directores y directoras al enfrentarse a los coros infantiles, surgen las necesidades básicas que se hubiesen esperado obtener durante su formación superior. Por ello, es imprescindible analizar y citar las sugerencias que este grupo profesional de la música expone.

El análisis muestra que la formación en pedagogía musical, en psicomotricidad, danzas básicas y expresión corporal, así como el conocimiento de la fisiología de la voz infantil, y la bibliografía musical para este tipo de grupos es de gran importancia durante la carrera académica. Así mismo, solicitan también énfasis en la enseñanza del canto.

Se puede observar la importante necesidad de renovar y actualizar los conceptos de la formación para la dirección coral. Las deficiencias en los distintos campos se hacen cada vez más grandes, y se reflejan principalmente en la calidad, debido a la competitividad internacional que evoluciona a través de los años. 
doi: http://dx.doi.org/10.15359/ree.21-1.5

URL: http://www.una.ac.cr/educare

CORREO: educare@una.cr

La adecuada formación ha de incluir profesionales dispuestos a formar en cultura coral infantil y técnicas vocales para niños latinoamericanos. Considero importante la experiencia en vivo de distintos coros de alto nivel para crear la conciencia en que si se puede y que se necesita crear expertos en la materia. Es importante incorporar profesionales en esta área en las universidades y centros de estudio formal que pretendan otorgar el título de directores corales. Es necesario cambiar el currículo de las carreras de Dirección Coral, ya que carecen de bases suficientes en canto para voces blancas y entrenamiento vocal adecuado. (Director 5)

Técnicas específicas para la dirección de coros infantiles. Métodos musicales pedagógicos para el trabajo con niños. Fisiología vocal en el niño. Manejo de ensambles corales infantiles. (Director 9)

\section{Conclusiones}

El director o directora se forma en distintas áreas que le convierten en profesional integral de la música. Los planes deestudio respecto a la dirección coral incluyen el desarrollo de destrezas prácticas (instrumento, canto, técnica del gesto, entre otros) o teóricas (historia, análisis, entre otros). La formación como profesional de la música desde la perspectiva individual suele ser realmente amplia y fuerte. No se pone en duda la calidad de la técnica del gesto que adquieren en su paso por la academia, o los conocimientos que se pueden adquirir en el análisis armónico, histórico y estructural de las partituras. Sin embargo, no se puede olvidar que la profesión del director o directora es, básicamente, la de líder musical, posición en la que todas las virtuosas ideas artísticas que fabrique en su pensamiento a través del análisis y su práctica individual deberán ser transmitidas al grupo musical que lidere.

Los coros infantiles con mayor razón se vuelven instituciones de enseñanza en distintas áreas. Si se recuerda lo que nos decía Ferrer (2009), nos damos cuenta en la importancia que tienen todos los sentidos en conjunto con la voz en el aprendizaje musical, así como el autoconocimiento que se adquiere a través del canto, no se limita a los aspectos musicales y físicos, sino también se abarca el desarrollo psicológico, social y moral.

Los directores y directoras de coros infantiles adquieren la responsabilidad de fomentar este desarrollo integral, independientemente de los objetivos de cada agrupación, para lo que es imprescindible que puedan poseer las suficientes herramientas y conocimientos para llevarlos a cabo. Es necesario que, como líderes musicales, sean conscientes de la diversidad que existe en un grupo al momento de hacer efectivas sus funciones artísticas. 
Para estas funciones resulta vital el dominio vocal. Si su trabajo gira alrededor de la formación de voces, su ensamble, cumplir objetivos estilísticos, tímbricos, y otras metas musicales; la aplicación de todos estos elementos desde la propia experiencia es imprescindible. De no hacerlo, la transmisión de estas ideas se torna en una difícil tarea. Sin embargo, a ello se debe agregar que la comprensión de la forma de aprender de las personas del grupo coral es lo que le da al director o directora las claves para transmitir, de manera más clara, sus ideas. Estos conceptos son los que la pedagogía en la dirección otorga a este líder musical. Podrá ser formado de la manera más virtuosa en el piano, en el canto o en la técnica del gesto, pero si no se poseen las herramientas para enseñar o transmitir las ideas, los objetivos no llegarán a su plenitud.

Por otro lado, en el aspecto médico, el director o directora coral infantil cuenta con responsabilidades de gran importancia. Molina et al. (2006) indican que los niños y niñas que cantan en los coros infantiles, contrario a lo que se podría esperar, presentan las mismas lesiones en sus cuerdas vocales respecto a quienes no lo hacen. Además, son claros, desde el punto de vista médico, en que gran cantidad de directores y directoras corales infantiles no tienen en cuenta una serie de conocimientos necesarios para desarrollar las voces blancas y, además, se desconocen las consecuencias que esto puede tener en la salud. Estos estudios advierten que estos grupos profesionales poseen, en este sentido, una responsabilidad ética y hasta legal.

La asignatura de coro en las escuelas de música llega a ser parte vital en la formación del músico o música, ya que es el espacio en el que se puede poner en práctica todos y cada uno de los aspectos musicales que se enseñan en la teoría. La comprensión de los distintos estilos musicales y sus compositores; la aplicación de elementos de articulación, fraseo, y todos aquellos que se aplican a la música son, en definitiva, más claros para quien se forma cuando lo vive por sí, a través de la experiencia, tal y como lo indica Ferrer (2009). Por ello, la formación universitaria de los directores y directoras corales debería contemplar los contenidos pedagógicos necesarios para que estos grupos profesionales puedan poseer las ideas claras en este aspecto, y defiendan estos argumentos en el salón de ensayos, a partir del propio trabajo artístico de estos líderes musicales.

De forma sintetizada, en la Tabla 7 se recogen por categorías, los resultados de los dos análisis realizados: 
doi: http://dx.doi.org/10.15359/ree.21-1.5

URL: http://www.una.ac.cr/educare

CORREO: educare@una.cr

Tabla 7: Síntesis de análisis realizado

\begin{tabular}{|c|c|c|}
\hline Planes de estudio & Costa Rica & España \\
\hline Área de Canto & $\begin{array}{l}\text { Se imparte la asignatura individualmente } \\
\text { durante } 3 \text { años, agregando un año más } \\
\text { en la especialización. }\end{array}$ & $\begin{array}{l}\text { Se imparte durante } 2 \text { años y de manera } \\
\text { grupal. }\end{array}$ \\
\hline Área de Pedagogía & $\begin{array}{l}\text { El plan de estudios incluye asignaturas } \\
\text { de pedagogía coral }\end{array}$ & $\begin{array}{l}\text { El plan de estudios no contiene ninguna } \\
\text { asignatura de pedagogía. }\end{array}$ \\
\hline \multicolumn{3}{|c|}{ Análisis de Entrevistas } \\
\hline $\begin{array}{l}\text { Categoría: } \\
\text { Formación de } \\
\text { directores } \\
\text { y directoras corales }\end{array}$ & $\begin{array}{l}\text { Una parte afirma tener asignaturas } \\
\text { específicas para la dirección coral } \\
\text { infantil. Otra parte indica que no los } \\
\text { poseen. La totalidad coincide en que } \\
\text { es escaso el material aportado, y en su } \\
\text { búsqueda por medios propios. }\end{array}$ & $\begin{array}{l}\text { Coinciden en la no existencia de asignaturas } \\
\text { específicas, y en la obtención de material por } \\
\text { sus propios medios o en cursos fuera de la } \\
\text { enseñanza superior. }\end{array}$ \\
\hline $\begin{array}{l}\text { Categoría: } \\
\text { Competencias del } \\
\text { director y directoras } \\
\text { de coros infantiles }\end{array}$ & $\begin{array}{l}\text { Pocos o nulos conocimientos o } \\
\text { utilización de métodos pedagógicos. } \\
\text { Hay discrepancia en argumentos y } \\
\text { dificultad para hacer descripciones de } \\
\text { manera objetiva y clara. }\end{array}$ & $\begin{array}{l}\text { Pocos conocimientos o utilización de } \\
\text { métodos pedagógicos. } \\
\text { Hay discrepancia e irregularidades para la } \\
\text { descripción objetiva de distintos aspectos. }\end{array}$ \\
\hline $\begin{array}{l}\text { Categoría: } \\
\text { Propuestas para } \\
\text { la formación } \\
\text { académica }\end{array}$ & $\begin{array}{l}\text { Se insiste en la progresiva } \\
\text { profesionalización del área coral } \\
\text { infantil, en que la formación en canto } \\
\text { y en pedagogía en las universidades } \\
\text { contenga más materiales y enseñanzas } \\
\text { en cuanto a los coros infantiles. }\end{array}$ & $\begin{array}{l}\text { Necesidad de conocer acerca de expresión } \\
\text { corporal, y otros aspectos de movimiento, así } \\
\text { como de elementos pedagógicos provenientes } \\
\text { de países que se han desarrollado más } \\
\text { ampliamente en el área coral infantil. }\end{array}$ \\
\hline
\end{tabular}

Nota: Elaboración propia.

Por todo lo expuesto anteriormente, podemos concluir que:

- La formación académica de los directores y directoras corales se enfoca principalmente en sus destrezas técnicas personales y no así en los recursos pedagógicos para transmitir sus ideas a las agrupaciones que dirigen.

- Por tanto, es necesario realizar una revisión y actualización de los planes de estudio en dirección coral, principalmente en las áreas de pedagogía y canto, en las universidades y centros de enseñanza superior de música de Costa Rica y España, de manera que la estructura de las asignaturas permita dotar, a profesionales de esta disciplina en su formación, de herramientas pedagógicas suficientes para el trabajo con coros infantiles. 
- Es éticamente necesario que los directores y directoras conozcan más a fondo las facultades físicas y musicales de las voces blancas y su cuidado.

- Es preciso que los directores y directoras se formen en metodologías pedagógicas del siglo XX, principalmente aquellas que se basan en el canto coral o el uso de la voz y el cuerpo, y que se mantienen vigentes en todo el mundo, como Kodály, Orff o Willems.

- A partir del conocimiento a fondo de estas metodologías, su correcta implementación adaptada a las realidades del país al que pertenece cada director o directora, así como el conocimiento de las pedagogías formuladas en Iberoamérica, es preciso incorporarlas en el proceso del conocimiento pedagógico de profesionales del área.

\section{Referencias}

Castro, M. (2003). Conjuntos vocales. San José, Costa Rica: Editorial de la Universidad de Costa Rica.

Consejo de Gobierno. (Jueves 16 de junio, 2011). Materias obligatorias para la especialidad de dirección. Boletín Oficial de la Comunidad de Madrid N. ${ }^{\circ} 141$. Recuperado de http://www. rcsmm.eu/estudios/plan-de-estudios/?m=2\&s=11

Ferrer, R. (2009). El canto coral y las orquestas infantiles, una educación en valores. Eufonía: Didáctica de la música, 45, 30-38.

Gustems, J. y Elgstrom, E. (2008). Guía práctica para la dirección de grupos vocales e instrumentales. Barcelona: Graó.

Ibarretxe, G. y Díaz, M. (Marzo, 2008). La figura del director de coros infantiles: Pasos hacia la profesionalización. Revista da abem, 19, 7-13. Recuperado de http://www. abemeducacaomusical.com.br/revistas/revistaabem/index.php/revistaabem/article/ view/254/185

Miró, C. (2011). Zoltán Kodály creador del arte del canto coral polifónico contemporáneo en Hungría vigencia y proyecciones de su obra. Revista NEUMA, 4(2), 10-50. Recuperado de http://musica.utalca.cl/DOCS/neuma/2011-2/Neuma UTAL 9-50.pdf

Molina, M. T., Fernández, S., Vázquez, F. y Urra, A. (2006). Voz del niño. Revista Médica Universidad de Navarra, 50(3), 31-43. Recuperado de http://dadun.unav.edu/bitstream/10171/35894/1/pdf.pdf

Piñeros, M. O. (2004). Introducción a la pedagogía vocal para coros infantiles. Bogotá: Ministerio de Cultura.

Universidad Nacional. Escuela de Música. (s. f.). Plan de estudio bachillerato en música con énfasis en: Interpretación y enseñanza de la dirección coral. Recuperado de http://www.una.ac.cr/ index.php/m-oferta-academica/direccion-coral-bachillerato-y-licenciatura-en-musica 